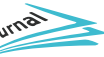

\title{
Orginal Article: \\ Factors Affecting the Caregiver Difficulties in Caring of Children With Cerebral Palsy
}

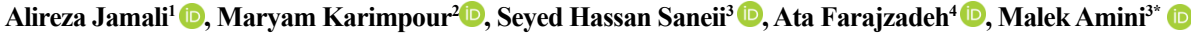 \\ 1. School of Rehabilitation Sciences, Iran University of Medical Sciences, Tehran, Iran. \\ 2. Department of Basic Sciences in Rehabilitation, Rehabilitation Research Center, School of Rehabilitation Sciences, Iran University of Medical \\ Sciences, Tehran, Iran. \\ 3. Department of Occupational Therapy, Rehabilitation Research Center, School of Rehabilitation Sciences, Iran University of Medical Sciences, \\ Tehran, Iran. \\ 4. Department of Occupational Therapy, School of Rehabilitation Sciences, Iran University of Medical Sciences, Tehran, Iran.
}

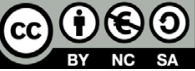

*This work has been published under CC BY-NC-SA 4.0 license.

\section{Article info:}

Received: 07 Apr 2020

Accepted: 23 May 2020

Available Online: 28 Oct 2020

Funding

This study was supported by Iran Universality of Medical Sciences (Grant No.:97-4-6-13539)

Conflict of interest

The authors declared no conflict of interest.

\section{ABSTRACT}

Background and Objectives: Cerebral Palsy $(\mathrm{CP})$ can trouble caregivers in the families of children with cerebral palsy. This study aimed to investigate the factors affecting caregiver troubles of the families of children with $\mathrm{CP}$.

Methods: In this cross-sectional study, 121 children with CP and their parents participated. Factors such as gross motor function, manual ability, communication function, eating and drinking abilities, seizure, IQ, age, gender, auditory and visual problems were evaluated in children, and their predictive power to the caregiver difficulties was measured.

Results: The Mean $\pm \mathrm{SD}$ of age of the children in the study was $9.7 \pm 4.6$ years. The linear regression results showed that none of the evaluated factors were predictors of caregiver difficulties.

Conclusion: The present study showed that none of the factors mentioned could predict caregivers' troubles. Future studies on the factors affecting the caregiver difficulty should be conducted to provide additional information or to draw more complex models to describe caregivers' difficulties in parents of children with $\mathrm{CP}$ in Iran.

Keywords: Cerebral palsy, Caregivers, Difficulties

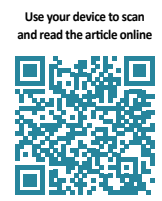

Crte this artice as Jamali A, Karimpour M, Saneii SH, Farajzadeh A, Amini M. Factors Affecting the Caregiver Difficulties in Caring of Children With Cerebral Palsy. Function and Disability Journal. 2020; 3:1-10. http://dx.doi.org/10.32598/fdj.3.66.1

doi http://dx.doi.org/10.32598/fdj.3.66.1

* Corresponding Author:

\section{Malek Amini, PhD.}

Address: Department of Occupational Therapy, Rehabilitation Research Center, School of Rehabilitation Sciences, Iran University of Medical Sciences, Tehran, Iran.

Tel: +98 (21) 2228051

E-mail: amini.m@iums.ac.ir
† What is "already known" in this topic:

Cerebral palsy is one of the disorders that impose great difficulty on children and their families. Many factors affect caregiver difficulty.

\section{What this article adds:}

None of the mentioned personal factors could predict Caregiver difficulty. 


\section{Introduction}

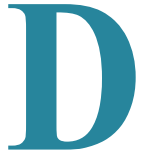

isability not only affects children with disabilities but also impacts their families [1]. The biggest impact of this disability is on these parents is coping with different needs and characteristics of their children [2]. Parents of children with Cerebral Palsy (CP) have a key role in meeting the needs of these children, pursuing treatment, and providing various care for their special needs [3]. The stress and difficulties which affect these parents play a key role in their performance and the way that they manage the child. Cerebral palsy is one of the disorders that impose great difficulty on children and their families $[4,5]$.

$\mathrm{CP}$ is a complex disorder of varying degrees of motor and cognitive impairments. $\mathrm{CP}$ is a non-progressive neurological injury that results from brain damage before birth, during birth, or early childhood [6]. Although the impairment is static, the cascade of motor and functional impairments continue throughout the person's life [2].

Although motor dysfunction is a major symptom of cerebral palsy, many children with CP have significant problems in their cognitive, sensory, communication, and social skills [7]. These limitations require care and support for these children, far greater than normal children. This condition can result in significant difficulties for the families of these children [8]. The caregiver's inconvenience reflects the potential negative impact of a patient's illness on caregivers and includes multiple psychological, physical, emotional, social, and financial problems and difficulties of patient care. This concept has a complex and multifaceted conceptual structure and usually occurs when the patient needs more care and resources $[9,10]$. According to the literature, caregiver difficulties can lead to mental and physical problems over the years [11]. Marrón et al. showed that the most important predictors of caregiver burden were the degree of disability, depression, and self-efficacy [12]. Sometimes family members of the patient who has a chronic illness are burdened with the patient's needs and problems. This is especially true for patients such as children with CP who are being cared at home [12].

Parents of children with CP are reported to have a high percentage of stress and caregiver problems [13]. These parents have higher levels of depression and anxiety, and typically experience lower life satisfaction, quality of life, and self-efficacy than parents of typicallydeveloped children $[14,15]$. Parkes et al. in a study on families and children with cerebral palsy in European countries, showed that parents of these children had a high degree of stress [16]. Pousada et al. found that caregiving burdens had a negative effect on the quality of life of caregivers and increased their stress too. They also mentioned that each society should demonstrate the factors affecting caregivers' burden to have the proper planning for this problem [17].

However, few studies have been conducted on the personal factors affecting the difficulties and burden of caregivers of children with CP in Iran [18]. The management of these caregiver difficulties has a significant impact on the child and the parents' function. Parents of children with CP are involved in daily care, child support, and coordination of services [3]. They play an important role in the rehabilitation of children with long-term disabilities and their health is of paramount importance [19]. The main question of this study is which factors affect the difficulties of caregivers of children with CP. Therefore, the present study was conducted to evaluate the personal factors affecting the difficulties of mothers of children with cerebral palsy in Iran.

\section{Materials and Methods}

\section{Study design}

The present study was a cross-sectional study conducted in Tehran City, Iran, in 2019.

\section{Study participants}

A multistage sampling method was used in this study to collect the study samples. At first, Tehran was divided into five parts: North, south, east, center, and west. In each of the five centers, a boys' school and a girls' school were selected for sampling. A number of students were randomly selected for sampling. Subsequently, research and informed consent forms were sent to the families of the children. Parents returned these forms after filling them out.

The inclusion criteria for the child were as follows: the child should be between 2 and 18 years old and be diagnosed with $\mathrm{CP}$, according to a neurologist report. The parental inclusion criteria were as follows: parents should be able to read and write in Persian and were interested in participating in the study. Parents who did not complete the consent form or the study tools were excluded from the research process.

Outcome measures 


\section{Caregiver Difficulties Scale (CDS)}

The Caregiver Difficulties Scale (CDS) was used to assess the caregivers of children with CP. The tool consists of 25 items, divided into 4 subtests of concern for the child ( 8 items), impact on self ( 7 items), support for caregiving ( 5 items), and social and economic strain (5 items) $[18,20]$. Each item receives a score of 1 to 4 . Higher scores indicate higher caregiver's difficulties. This tool has sufficient validity and reliability among Iranian mothers of children with CP [21].

\section{The Gross Motor Function Classification System (GMFCS)}

In this study, the Gross Motor Function Classification System (GMFCS) was used to classify the gross motor ability of children. GMFCS is based on active movement and emphasizes on gross motor movements. This classification system consists of 5 levels. In this system, differences are characterized by the ability to move long distances, the existence of functional limitations, the need for manual aids such as walkers, crutches, and canes or wheeled vehicles such as wheelchairs [22]. This scale is a valid and reliable tool for assessing gross motor function in children with $\mathrm{CP}$. The reliability of the instrument is 0.93 [23].

\section{The Manual Ability Classification System (MACS)}

The Manual Ability Classification System (MACS) is a human hand motion classification system that describes how children aged 4 to 18 years with $\mathrm{CP}$ use their hands in daily activities. This tool focuses on using both hands together. The classification system uses five levels to categorize the functional levels of the hand. Level one is an indicator of minimal hand dysfunction. At this level, the child only has problems with tasks that require speed and accuracy. Level 5 represents the most impaired, the inability to manipulate objects, and limited ability to perform the simplest tasks [24]. This tool has good validity and reliability. The intra-cluster kappa coefficient of this questionnaire is 0.75 [25].

\section{Communication Function Classification System (CFCS)}

The Communication Function Classification System (CFCS) was used to assess the level of communication ability of children with cerebral palsy. This classification system is based on the effectiveness of the communication between the sender and receiver of information. This system classifies all communication modes, including speech, gesture, facial expression, and alternative communication methods. The reliability of the questionnaire is 0.74 [26].

Eating and Drinking Ability Classification System (EDACS)

The Eating And Drinking Ability Classification System (EDACS) system is used to measure a child's ability to eat and drink. This classification system includes the safety (aspiration and choking) of eating and drinking, the efficiency (food waste and speed of eating), and the amount of assistance a person needs while eating. It has good validity and reliability in children with CP. The Intraclass Correlation Coefficient (ICC) for this questionnaire is 0.86 and the kappa coefficient is 0.45 [27].

Cognitive level assessment

SPARCLE stands for the PARticipation Study of Children with CP Living in Europe. SPARKEL scale was used to assess participants' cognitive ability. This form is taken from the Sparkle project. The Sparkle scale categorizes children's cognitive ability according to the International Classification of Diseases, $10^{\text {th }}$ revision (ICD10). Children who score below 50 on this scale have severe cognitive impairment. A score of 5070 indicates mild cognitive impairment, and such children may suffer from learning disabilities [28].

\section{Demographic questionnaire}

A demographic questionnaire was used to collect demographic data, including child age, type of cerebral palsy, gender, use of assistive devices, visual and hearing problems, parent's age, the gender of parents, type of residence, level of education, and parents' occupation.

\section{Study procedure}

In this study, one occupational therapist was responsible for data collection and necessary communications. After obtaining the necessary permits, this person (second author) went to schools and collect information on children who were eligible to participate in the study. After collecting the demographic information and performing the cognitive test, all other forms, including the informed consent form, GMFCS, EDACS, CFCS, and $\mathrm{CDS}$ questionnaires were sent for parents. when the parents returned the forms, the therapist also evaluated the GMFCS, EDACS, and CFCS for assurance. 
Data analysis

To evaluate the data and investigate the relationships between them, SPSS V. 24 sofwaer was used. The linear regression statistical test was used to investigate the predictive power of different variables (personal factors) on the dependent variable (caregivers' difficulties).

\section{Results}

Demographic variables of caregiver difficulties are shown in Table 1.

Table 2 presents the Mean \pm SD of the quantitative variables and their relationship with caregiver difficulties. The results of the regression modeling which is presented in the following tables show that none of these factors are good predictors of parental difficulties for children with CP. Of 121 chil- dren participating in the study, $76(62.8 \%)$ were male and $45(37.2 \%)$ were female. The Mean \pm SD of the age of the children in the study was $9.7 \pm 4$.6 years. Table 3 presents information on demographic variables.

\section{Discussion}

The study aimed to investigate the factors affecting caregiver difficulties of parents with $\mathrm{CP}$ children. The results showed that none of the factors could be a good predictor of caregiver difficulty in the families of children with CP. At first glance, it seems surprising that none of these 12 factors could predict the caregiver difficulty of families of children with $\mathrm{CP}$, but it should be noted that caregiver difficulty is a complex and multi-faceted issue and sometimes in various diseases had no significant relationship with disease severity [29]. Besides, all 12 factors examined were related to the child, not the child's caregivers. In research designed for the

Table 1. Demographic variables of caregiver difficulties

\begin{tabular}{|c|c|c|c|}
\hline \multirow{2}{*}{\multicolumn{2}{|c|}{ Variables }} & \multirow{2}{*}{ No. } & \multirow{2}{*}{$\begin{array}{c}\text { Mean } \pm \text { SD } \\
\text { Caregiver Difficulties }\end{array}$} \\
\hline & & & \\
\hline \multirow{2}{*}{ Child's gender } & Male & 75 & $66.6 \pm 9.5$ \\
\hline & Female & 45 & $61.7 \pm 12.2$ \\
\hline \multirow{4}{*}{ Mother's education level } & Illiterate & 3 & $60.3 \pm 12.9$ \\
\hline & Elementary or secondary & 26 & $66 \pm 11.3$ \\
\hline & Diploma & 56 & $66 \pm 10.8$ \\
\hline & Bachelor or Master's degree & 35 & $65.4 \pm 12.2$ \\
\hline \multirow{4}{*}{ Father's education level } & Illiterate & 2 & $51 \pm 7.8$ \\
\hline & Elementary and secondary & 29 & $67.5 \pm 9.8$ \\
\hline & Diploma & 48 & $65.7 \pm 11.5$ \\
\hline & Bachelor and Master's degree & 40 & $65.1 \pm 11.6$ \\
\hline \multirow{2}{*}{ Mother's job } & Housewife & 100 & $65.9 \pm 10.8$ \\
\hline & Employed or self-employed & 19 & $65.2 \pm 14.2$ \\
\hline \multirow{3}{*}{ Father's job } & Employed & 41 & $62.9 \pm 11.9$ \\
\hline & Self-employed & 71 & $66.7 \pm 10.6$ \\
\hline & Jobless & 6 & $60.1 \pm 10.7$ \\
\hline \multirow{5}{*}{ Region } & North & 27 & $64 \pm 10.8$ \\
\hline & South & 54 & $67.7 \pm 10.9$ \\
\hline & East & 5 & $63.2 \pm 5.1$ \\
\hline & West & 8 & $68.6 \pm 12.2$ \\
\hline & Center & 25 & $64.7 \pm 13$ \\
\hline \multirow{2}{*}{ Rehab services } & Yes & 93 & $64.8 \pm 10.6$ \\
\hline & No & 27 & $70.4 \pm 13$ \\
\hline
\end{tabular}




\begin{tabular}{|c|c|c|c|}
\hline \multirow{2}{*}{\multicolumn{2}{|c|}{ Variables }} & \multirow{2}{*}{ No. } & \multirow{2}{*}{$\begin{array}{c}\text { Mean } \pm S D \\
\text { Caregiver Difficulties }\end{array}$} \\
\hline & & & \\
\hline \multirow{6}{*}{ Cerebral palsy type } & Spastic hemiplegia & 42 & $67.8 \pm 11.7$ \\
\hline & Spastic diplegia & 13 & $61.5 \pm 10.4$ \\
\hline & Spastic quadriplegia & 38 & $64.5 \pm 10.8$ \\
\hline & Athetoid & 11 & $67.3 \pm 12.1$ \\
\hline & Ataxic & 6 & $65.6 \pm 9.7$ \\
\hline & Dystonic & 7 & $64.2 \pm 10.6$ \\
\hline \multirow{2}{*}{ Visual impairment } & Poor vision & 24 & $65.7 \pm 11.1$ \\
\hline & No problem & 94 & $65.9 \pm 11.5$ \\
\hline \multirow{2}{*}{ Auditory impairment } & Yes & 2 & $67.5 \pm 7.8$ \\
\hline & No problem & 117 & $35.8 \pm 11.4$ \\
\hline \multirow{2}{*}{ Seizure } & Yes & 31 & $64.3 \pm 10.2$ \\
\hline & No & 89 & $66.4 \pm 11.6$ \\
\hline \multirow{2}{*}{ Walking ability } & Yes & 53 & $67.3 \pm 11.7$ \\
\hline & No & 67 & $64.7 \pm 10.9$ \\
\hline \multirow{3}{*}{ IQ level } & $>70$ & 36 & $67.9 \pm 13$ \\
\hline & $50-70$ & 39 & $64.9 \pm 11.4$ \\
\hline & $<50$ & 44 & $65 \pm 9.7$ \\
\hline \multirow{5}{*}{$\begin{array}{l}\text { The manual ability classification } \\
\text { system }\end{array}$} & 1 & 26 & $67.3 \pm 14.4$ \\
\hline & 2 & 23 & $68 \pm 11.8$ \\
\hline & 3 & 19 & $64 \pm 11.3$ \\
\hline & 4 & 26 & $64.5 \pm 9$ \\
\hline & 5 & 25 & $65.2 \pm 10.1$ \\
\hline \multirow{5}{*}{$\begin{array}{l}\text { The gross motor function classifica- } \\
\text { tion system }\end{array}$} & 1 & 12 & $67 \pm 13.2$ \\
\hline & 2 & 35 & $67.7 \pm 11.5$ \\
\hline & 3 & 14 & $69.5 \pm 12.5$ \\
\hline & 4 & 24 & $63.2 \pm 9.7$ \\
\hline & 5 & 34 & $63.9 \pm 10.9$ \\
\hline \multirow{5}{*}{$\begin{array}{l}\text { The communication function clas- } \\
\text { sification system }\end{array}$} & 1 & 41 & $68.4 \pm 12.8$ \\
\hline & 2 & 20 & $65.5 \pm 10$ \\
\hline & 3 & 21 & $64.2 \pm 12$ \\
\hline & 4 & 10 & $61.3 \pm 6.4$ \\
\hline & 5 & 27 & $65.3 \pm 10.4$ \\
\hline \multirow{5}{*}{$\begin{array}{l}\text { The eating and drinking ability clas- } \\
\text { sification system }\end{array}$} & 1 & 57 & $67 \pm 12.4$ \\
\hline & 2 & 32 & $65.1 \pm 9.4$ \\
\hline & 3 & 17 & $63.2 \pm 9.7$ \\
\hline & 4 & 10 & $62.9 \pm 10.7$ \\
\hline & 5 & 3 & $75.6 \pm 18.6$ \\
\hline
\end{tabular}


Table 2. The Mean \pm SD of quantitative variables and their relationship with caregivers' difficulties

\begin{tabular}{|c|c|c|c|c|}
\hline \multirow{2}{*}{ Variables } & \multirow{2}{*}{ No. } & \multirow{2}{*}{ Mean士SD } & \multicolumn{2}{|c|}{ Correlation } \\
\hline & & & $\mathbf{R}$ & Sig. \\
\hline Child's age & 121 & $9.7 \pm 4.6$ & 0.1 & 0.25 \\
\hline Father's age & 116 & $42.7 \pm 6.9$ & 0.06 & 0.46 \\
\hline Mother's age & 121 & $38.2 \pm 6.2$ & 0.09 & 0.3 \\
\hline
\end{tabular}

validity and reliability of the burden-related questionnaires, caregiver-related factors are usually more correlated with caregiver difficulty than the patient-related factors [20,30].

In a study by Whittingham et al. on the burden of care for the families of children with $\mathrm{CP}$, child behavior, parental coping, and experiential avoidance were the best predictors of caregiving, of which 2 are related to parental characteristics [31].

In a study on several children with $\mathrm{CP}$ and their parents, Champa et al. found that parental contextual factors such as low income, rural residence, and male sex were mostly associated with parental care [18].

In 2000, Hwa and colleagues conducted a study on Korean families and their children. The results showed that the degree of children's handicap, familial relationship with the children, caregiver's health status, age of the children, and duration of treatment had the highest correlation with the caregiver difficulty [32].

Boztepe's study of the caregiver difficulty in families of children with $\mathrm{CP}$ who has leukemia showed that the presence of depression in the mother and the severity of the

Table 3. Stepwise linear regression for predicting caregiver difficulties

\begin{tabular}{|c|c|c|c|c|c|c|c|}
\hline \multirow{2}{*}{ Variables } & \multicolumn{2}{|c|}{$\begin{array}{l}\text { Unstandardized } \\
\text { Coefficients }\end{array}$} & \multirow{2}{*}{$\begin{array}{c}\begin{array}{c}\text { Standardized } \\
\text { Coefficients }\end{array} \\
\text { Beta }\end{array}$} & \multirow{2}{*}{$\mathbf{t}$} & \multirow{2}{*}{ Sig. } & \multicolumn{2}{|c|}{ 95.0\% Confidence Interval for B } \\
\hline & Model B & Std. Error & & & & Lower Bound & $\begin{array}{l}\text { Upper } \\
\text { Bound }\end{array}$ \\
\hline Constant & 53.636 & 9.620 & - & 5.576 & 0.000 & 34.568 & 72.704 \\
\hline Age & 0.115 & 0.293 & 0.038 & 0.392 & 0.696 & -0.466 & 0.696 \\
\hline Caregiver & 2.471 & 4.757 & 0.047 & 0.519 & 0.605 & -6.959 & 11.901 \\
\hline visual & 0.468 & 2.941 & 0.015 & 0.159 & 0.874 & -5.361 & 6.298 \\
\hline $\begin{array}{l}\text { Auditory } \\
\text { problem }\end{array}$ & 2.827 & 8.095 & 0.032 & 0.349 & 0.728 & -13.219 & 18.873 \\
\hline Seizure & 1.366 & 2.969 & 0.043 & 0.460 & 0.646 & -4.519 & 7.251 \\
\hline Walking & -6.301 & 3.505 & -0.226 & -1.798 & 0.075 & -13.248 & 0.647 \\
\hline CP type & -0.319 & 0.876 & -0.034 & -0.364 & 0.716 & -2.055 & 1.417 \\
\hline IQ & 0.007 & 1.681 & 0.000 & 0.004 & 0.997 & -3.326 & 3.340 \\
\hline GMFCS & -1.821 & 1.289 & -0.182 & -1.413 & 0.161 & -4.376 & 0.734 \\
\hline MACS & 0.665 & 1.077 & 0.070 & 0.618 & 0.538 & -1.469 & 2.800 \\
\hline CFCS & 2.290 & 1.018 & 0.262 & 2.249 & 0.027 & 0.272 & 4.308 \\
\hline EDACS & 1.020 & 1.494 & 0.082 & 0.683 & 0.496 & -1.942 & 3.982 \\
\hline
\end{tabular}

CP: Cerebral Palsy; GMFCS: Gross Motor Function Classification System; MACS: Manual Ability Classification System; CFCS: Communication Function Classification System; EDACS: Eating and Drinking Ability Classification System; 
illness had the highest relationship with the caregiver difficulty [33].

Marrón et al. conducted a study in 2013 to evaluate the factors affecting parental care burden on children with $\mathrm{CP}$ in Spain. In this study, they used a regression model to analyze the obtained data. In their study, the degree of disability, parental depression, and self-efficacy had the highest association with caregiver difficulty in children with CP [34].

As observed in the above studies, caregiver-related factors were more related to the intensity of caregiver difficulty. Most of the mentioned studies have attempted to measure the correlation between child care and parent-child factors. It should be noted that, unlike correlation, which measures correlative factors, regression tries to establish causal and predictive relationships. Two or more variables can be correlated, but not necessarily predict each other [35]. In our study, none of the factors mentioned as independent variables (GMFCS, MACS, EDACS, CFCS, seizure, IQ, age, gender, and auditory and visual problem) cannot predict caregiver difficulty but it may correlate with these factors.

It should be noted that the attitudes of families and individuals about disabilities are very influential on caregiver difficulty. If parents have negative attitudes about disabilities, they may experience more psychological stress, too. In Iranian culture, a family of a CP child at level 2 in GMFCS may feel significant pressure to raise their child, but on the other hand, a family of a CP child at level 5 in GMFCS may accept this issue and do not get into a serious mental pressure. Despite investigating various factors in children with CP, the main limitation of this study was not using factors measuring caregiver-related issues. Future studies could also address these areas. Besides, the results will be more reliable if future studies use a larger sample size.

\section{Conclusion}

Caregiver difficulty is a multifaceted and complex issue that can be influenced by various factors. Our study showed that none of the factors mentioned could predict caregiver difficulty. Future studies on factors affecting the caregiver difficulty should be conducted to provide additional information or to draw more complex models to describe caregiver difficulty in parents of children with cerebral palsy.

\section{Ethical Considerations}

\section{Compliance with ethical guidelines}

This study was approved by the Ethics Committee of Iran University of Medical Sciences (IR.IUMS. REC.1397.1170). The participants signed an informed consent form after being informed of the privacy policy as well as the purpose, importance, methods, and risks associated with this study.

\section{Funding}

This study was supported by Iran Universality of Medical Sciences (Grant No.:97-4-6-13539)

\section{Authors' contributions}

Project design and supervise, final approval of the version to be published, and interpreting and discussing Results: Alireza Jamali and Malek Amini; Data collection: Maryam Karimpour and Ata Farajzadeh; Statistical analysis: Seyed Hassan Sanei.

\section{Conflict of interest}

The authors declared no conflict of interest.

Acknowledgment:

We appreciate all participants of this study.

\section{References}

[1] Burke MM, Hodapp RM. Relating stress of mothers of children with developmental disabilities to family-school partnerships. Intellect Dev Disabil. 2014; 52(1):13-23. [DOI:10.1352/1934-955652.1.13] [PMID]

[2] Vohra R, Madhavan S, Sambamoorthi U, St Peter C. Access to services, quality of care, and family impact for children with autism, other developmental disabilities, and other mental health conditions. Autism. 2014; 18(7):815-26. [DOI:10.1177/1362361313512902] [PMID] [PMCID]

[3] Hu X, Wang M, Fei X. Family quality of life of Chinese families of children with intellectual disabilities. J Intellect Disabil Res. 2012; 56(1):30-44. [DOI:10.1111/j.1365-2788.2011.01391.x] [PMID]

[4] Rentinck I, Ketelaar M, Jongmans M, Gorter J. Parents of children with cerebral palsy: A review of factors related to the process of adaptation. Child Care Health Dev. 2007; 33(2):161-9. [DOI:10.1111/ j.1365-2214.2006.00643.x] [PMID]

[5] Carona C, Crespo C, Canavarro M. Similarities amid the difference: Caregiving burden and adaptation outcomes in dyads of parents and 
their children with and without cerebral palsy. Res Dev Disabil. 2013; 34(3):882-93. [DOI:10.1016/j.ridd.2012.12.004] [PMID]

[6] Novak I, Mcintyre S, Morgan C, Campbell L, Dark L, Morton N, et al. A systematic review of interventions for children with cerebral palsy: State of the evidence. Dev Med Child Neurol. 2013, 55(10):885-910. [DOI:10.1111/dmcn.12246] [PMID]

[7] Brossard-Racine M, Hall N, Majnemer A, Shevell MI, Law M, Poulin C, et al. Behavioural problems in school age children with cerebral palsy. Eur J Paediatr Neurol. 2012; 16(1):35-41. [DOI:10.1016/j.ejpn.2011.10.001] [PMID]

[8] Byrne M, Hurley D, Daly L, Cunningham C. Health status of caregivers of children with cerebral palsy. Child Care Health Dev. 2010; 36(5):696-702. [DOI:10.1111/j.1365-2214.2009.01047.x] [PMID]

[9] Applebaum A, Bevans M, Son T, Evans K, Hernandez M, Giralt S, et al. A scoping review of caregiver burden during allogeneic HSCT: Lessons learned and future directions. Bone marrow transplantation. Bone Marrow Transplant. 2016; 51(11):1416-22. [DOI:10.1038/ bmt.2016.164] [PMID] [PMCID]

[10] Jamali AR, Mehraban AH, Amini M. Translation, face and content validity of burden scale for family caregivers. Middle East J Rehabi Health Stud. 2018 (In Press); 5(1):e62424 [DOI:10.5812/mejrh.62424]

[11] Dambi JM, Jelsma J, Mlambo T, Chiwaridzo M, Dangarembizi-Munambah N, Corten L. An evaluation of psychometric properties of caregiver burden outcome measures used in caregivers of children with cerebral palsy: A systematic review protocol. Syst Rev. 2016; 5(1):42. [DOI:10.1186/s13643-016-0219-3]

[12] Rosland A-M, Piette JD. Emerging models for mobilizing family support for chronic disease management: A structured review. Chronic Illn. 2010; 6(1):7-21. [DOI:10.1177/1742395309352254] [PMID] [PMCID]

[13] CheshireA, Barlow JH, Powell LA. The psychosocial well-being of parents of children with cerebral palsy: A comparison study. Disabil Rehabil. 2010; 32(20):1673-7. [DOI:10.3109/09638281003649920] [PMID]

[14] Eker L, Tüzün EH. An evaluation of quality of life of mothers of children with cerebral palsy. Disabil Rehabil. 2004; 26(23):1354-9. [DOI:10.1080/09638280400000187] [PMID]

[15] Ong L, Afifah I, Sofiah A, Lye M-S. Parenting stress among mothers of Malaysian children with cerebral palsy: Predictors of childand parent-related stress. Ann Trop Paediatr. 1998; 18(4):301-7. [D OI:10.1080/02724936.1998.11747964] [PMID]

[16] Parkes J, Caravale B, Marcelli M, Franco F, Colver A. Parenting stress and children with cerebral palsy: A European cross-sectional survey. Dev Med Child Neuro. 2011; 53(9):815-21. [DOI:10.1111/ j.1469-8749.2011.04014.x] [PMID]

[17] Pousada M, Guillamón N, Hernández-Encuentra E, Muñoz E, Redolar D, Boixadós M, et al. Impact of caring for a child with cerebral palsy on the quality of life of parents: a systematic review of the literature. J Dev Phys Disabil. 2013; 25(5):545-77. [DOI:10.1007/ s10882-013-9332-6]

[18] Wijesinghe CJ, Cunningham N, Fonseka P, Hewage CG, Østbye T. Factors associated with caregiver burden among caregivers of children with cerebral palsy in Sri Lanka. Asia Pac J Public Healt. 2015; 27(1):85-95. [DOI:10.1177/1010539514548756] [PMID]

[19] Dambi JM, Jelsma J. The impact of hospital-based and community based models of cerebral palsy rehabilitation: A quasi-experimental study. BMC Pediatr. 2014; 14(1):301. [DOI:10.1186/s12887-0140301-8] [PMID] [PMCID]

[20] Wijesinghe C, Fonseka P, Hewage CJCMJ. The development and validation of an instrument to assess caregiver burden in cerebral palsy: Caregiver difficulties scale. Ceylon Med J. 2013; 58(4):1627. [DOI:10.4038/cmj.v58i4.5617] [PMID]

[21] Farajzadeh A, Amini M, Maroufizadeh S, Wijesinghe CJJOtihc. Caregiver Difficulties Scale (CDS): Translation and psychometric evaluation among Iranian mothers of cerebral palsy children. Occup Ther Health Care. 2018; 32(1):28-43. [DOI:10.1080/07380577.201 7.1422607] [PMID]

[22] Palisano R, Rosenbaum P, Walter S, Russell D, Wood E, Galuppi BJDM, et al. Development and reliability of a system to classify gross motor function in children with cerebral palsy. Dev Med Child Neurol. 1997; 39(4):214-23. [DOI:10.1111/j.1469-8749.1997. tb07414.x] [PMID]

[23] Wood E, Rosenbaum PJDm, neurology c. The gross motor function classification system for cerebral palsy: A study of reliability and stability over time. Dev Med Child Neurol. 2000; 42(5):292-6. [DOI:10.1017/S0012162200000529] [PMID]

[24] Eliasson A-C, Krumlinde-Sundholm L, Rösblad B, Beckung E Arner M, Öhrvall A-M, et al. The Manual Ability Classification System (MACS) for children with cerebral palsy: scale development and evidence of validity and reliability. DMCN. 2006; 48(7):549-54. [DOI:10.1111/j.1469-8749.2006.tb01313.x]

[25] Riahi A, Rassafiani M, Akbarfahimi N, Karimloo MJjosc. [To determine the reliability and validity of the Persian translation of the manual ability classification system for children with cerebral palsy (Persian)]. J Except Child. 2012; 12(2):17-25. http://joec.ir/article1-148-fa.htm

[26] Soleymani Z, Joveini G, Baghestani ARJPn. The Communication Function Classification System: Cultural adaptation, validity, and reliability of the Farsi version for patients with cerebral palsy. Pediatr Neurol. 2015; 52(3):333-7. [DOI:10.1016/j.pediatrneurol.2014.10.026] [PMID]

[27] Sellers D, Mandy A, Pennington L, Hankins M, Morris CJDM, Neurology C. Development and reliability of a system to classify the eating and drinking ability of people with cerebral palsy. Dev Med Child Neurol. 2014; 56(3):245-51. [DOI:10.1111/dmcn.12352] [PMID]

[28] Colver AJBph. Study protocol: SPARCLE-a multi-centre European study of the relationship of environment to participation and quality of life in children with cerebral palsy. BMC Public Health 2006; 6(1):105. [DOI:10.1186/1471-2458-6-105] [PMID] [PMCID]

[29] Luttik ML, Jaarsma T, Veeger N, Tijssen J, Sanderman R, van Veldhuisen DJ. Caregiver burden in partners of Heart Failure patients: Limited influence of disease severity. Eur J Heart Fail. 2007; 9(6-7):695701. [DOI:10.1016/j.ejheart.2007.01.006] [PMID]

[30] Graessel E, Berth H, Lichte T, Grau H. Subjective caregiver burden: Validity of the 10-item short version of the Burden Scale for Family Caregivers BSFC-s. BMC Geriatr. 2014; 14(1):23. [DOI:10.1186/1471-2318-14-23] [PMID] [PMCID]

[31] Whittingham K, Wee D, Sanders MR, Boyd R. Predictors of psychological adjustment, experienced parenting burden and chronic sorrow symptoms in parents of children with cerebral palsy. Child Care Health Dev. 2013; 39(3):366-73. [DOI:10.1111/j.13652214.2012.01396.x] [PMID] 
[32] Lee HJ, Eo YS. [A study on family functioning and burden of parents with cerebral palsy children (Korean)]. Korean J Child Health Nursing. 2000; 6(2):199-211. https://www.e-chnr.org/upload/pdf/ jkachn-6-199.pdf

[33] Boztepe H, Çınar S, Ay A, Kerimoğlu Yıldız G, Kılıç C. Predictors of caregiver burden in mothers of children with leukemia and cerebral palsy. J Psychosoc Oncol. 2019; 37(1):69-78. [DOI:10.108 0/07347332.2018.1489441] [PMID]

[34] Marrón EM, Redolar-Ripol D, Boixadós M, Nieto R, Guillamón $\mathrm{N}$, Hernández E, et al. Burden on caregivers of children with cerebral palsy: Predictors and related factors. Universitas Psychologica. 2013; 12(3):767-77. [DOI:10.11144/Javeriana.UPSY12-3.bccc]

[35] Miles J, Shevlin M. Applying regression and correlation: A guide for students and researchers: California: SAGE Publications; 2001. 
